\title{
Interrelation between Acute Phase Response with Altered Level of Serum Orosomucoid and Glycemic status in Newly Developed Adult as Well as Adolescent Diabetic Patients
}

\author{
Mohiuddin SS ${ }^{*}$ and Manjrekar $\mathrm{P}^{2}$ \\ 1Department of Biochemistry, Imam Abdulrahman Bin Faisal University, Kingdom of \\ Saudi Arabia \\ ${ }^{2}$ Department of Biochemistry, Manipal University, India
}

\section{Research Article \\ Volume 2 Issue 3}

Received Date: October 07, 2018

Published Date: October 19, 2018

*Corresponding author: Shamim Shaikh Mohiuddin, Assistant Professor, Department of Biochemistry, College of Medicine, Imam Abdulrahman Bin Faisal University, PO box- 1982, Dammam- 31441, Kingdom of Saudi Arabia, Email: smohiuddin@iau.edu.sa

\section{Abstract}

Orosomucoid is an acute phase protein and is associated with inflammation. Following an acute inflammatory episode increased levels of orosomucoid used to be observed. The clinical value of orosomucoid is currently limited to monitoring the acute phase reaction. The interrelation between cytokine mediated acute inflammatory response and elevation of plasma orosomucoid level of adult type 2 diabetic patients are almost fully established and well recognized but the correlation of inflammatory status with orosomucoid level with glycemic status in adolescent type 1 diabetic patients are still contradictory and under investigation. In this present study we tried to establish the interrelation of orosomucoid level as an indicator of acute inflammatory condition with glycemic status in case of adult as well as adolescent diabetic patients. The plasma levels of orosomucoid were determined for twenty-five newly diagnosed adult type 2 and twelve adolescent type 1 diabetic patients. Thirty normal controls were also chosen matching with age and sex with the patients. Although there are vast variation in results regarding the interrelation between the status of serum orosomucoid level as an low grade chronic inflammatory markers with glycemic status in case of adult as well as adolescent diabetic patient and but after the analysis of data obtained in our present study we can say with conviction that the interrelation of this level are well corelated in case of adult type 2 diabetic patient but in case of adolescent patients its still in contradictory phase and for definitive diagnosis it obviously required further study, investigation and follow up.

Keywords: Type 1 diabetes; Type 2 diabetics chronic low-grade inflammation; $\alpha 1$ - acid glycoprotein; Orosomucoid 


\section{Open Access Journal of Endocrinology}

\section{Introduction}

Type 1 diabetes which is observing for about $90 \%$ of cases is the predominant form of diabetes during childhood and adolescence, although increasing number of obesity epidemic in childhood are often associated with childhood onset type 2 diabetes [1,2]. The major etiological factors for onset of childhood type 1 diabetes mellitus are the synergistic effects of environmental, genetic and immunological factors which used to destruct the pancreatic $\beta$-cells mass. The main contributing factor for occurrence of type 1 diabetes in individuals of genetic susceptibility is due to process of autoimmunity that used to develop several months or even years which used to destroy the $\beta$-cells mass [3]. Complications of diabetes put a heavy burden for patients, family members and health provider. The significant improvements in diabetes care used to achieve because of fighting against each individual complication, especially for microvascular complications, yet macroangiopathy remains a major source of morbidity and mortality. By understanding of the complex pathophysiology for development of adult as well as childhood diabetes, prevention of the development of complication and treatment approach can be achieved [4]. Several inflammatory markers have been involved for detection of the incidence of diabetes, including C-reactive protein (CRP) [5], sialic acid, white blood cells, interleukin (IL) 6 [6] and orosomucoid [7] Several studies have shown that circulating markers of inflammation, acute phase reactants or interleukin-6 (IL-6) are strong predictors of the development of type 2 diabetes [8,9]. T-2 ((Type 2) diabetes mellitus is seen to be related with increased blood concentrations of markers of the acutephase response known as $\alpha 1$ acid glycoprotein and also interleukin-6, which is the main cytokine mediator of the response. The dyslipidemia which is very much commonly seen in Type 2 diabetes (hypertriglyceridemia and low serum levels of HDL cholesterol) is also a feature of natural and experimental acute-phase reactions. Out of these all proteins our study of interest in this project is orosomucoid, also known as $\alpha 1$-acid glycoprotein (AGP).

Schmidt's excellent review [10] covers historical aspects of work that dates back the 1940's when the seromucoid proteins were first described. The major portion of plasma seromucoids has since been recognized as orosomucoid or $\alpha 1$ - acid glycoprotein. Among the plasma orosomucoid is unique because of its low pI which is 2.7-3.5. Its molecular weight is $\sim 40000$. It contains $45 \%$ carbohydrate as hexose, hexosamine and sialic acid in equal proportion. The antigenic determinant (epitope) utilized in immunochemical assays, however, is on the polypeptide moiety. It has an excellent solubility in water and polar solvents and has a high negative charge density at $\mathrm{pH}$ 7.4. Treatment with neuraminidase followed by isoelectric focusing reveals polymorphism in the $\alpha 1$ region. Though polymorphism has no known clinical significance but because of its orosomucoid migration on agarose or cellulose electrophoresis may differ slightly from one specimen to another. Orosomucoid is associated with inflammation. Following an acute inflammatory episode increased levels of orosomucoid observed, i.e. it is an acute phase reactant. A certain degree of homology exists among the amino acid sequence of orosomucoid, the immunoglobins and haptoglobin $\alpha$ chain which suggest a common ancestry or role of the immune system [11]. Early work indicated that the liver was the only site of synthesis of orosomucoid. More recent studies have shown that under certain well-defined condition, some tumors are able to synthesize orosomucoid. Catabolism of orosomucoid proceeds first by desialation followed by rapid degradation in liver within minutes. The clinical value of orosomucoid determination is currently limited to monitoring the acute phase reaction. However increased serum occurs in rheumatoid arthritis, systemic lupus erythematosus, Crohn's disease, and malignant neoplasms, especially those with metastasis and large tumor masses and myocardial infarction. Decreased level occurs in malnutrition, severe hepatic damage and severe protein loosing gastroenteropathy [11]. The acute-phase proteins are mainly synthesized in the liver, stimulated by cytokines, mainly interleukin (IL)-1, IL-6 and tumor necrosis factor (TNF) which are produced in macrophages, monocytes, endothelium and many other cells in the body [12]. The acute-phase proteins have many activities that in general contribute to host defense, healing and adaptation to insult. For example, proteinase inhibitors such asa1-antitrypsin control proteinases released by phagocytes, fibrinogen has a major role in hemostasis, and ceruloplasmin, haptoglobin and metallothionine are antioxidants protecting against toxic oxygen metabolites produced at the site of injury and inflammation [13].

\section{Materials and Methods}

\section{Aims and Objective}

1. To detect the elevation of orosomucoid, if any, in newly diagnosed untreated adult type 2 diabetic and adolescent type 1 diabetes mellitus patient

2. Compare the level of this inflammatory marker of newly diagnosed untreated type 2 diabetes mellitus with their glycemic status. 


\section{Open Access Journal of Endocrinology}

3. Compare the level of this inflammatory marker of newly diagnosed untreated type 1 diabetes mellitus with their glycemic status.

\section{Participants}

Subjects were selected from various clinics and hospitals in Mangalore, India. Height and weight of all subjects were recorded, and body mass index was calculated. None of the sixty-seven volunteers did not suffer from chronic inflammatory diseases like asthma, chronic bronchitis, and rheumatoid arthritis as was ascertained by clinical history. The study was approved by institutional ethical committee.

\section{Materials}

$5 \mathrm{ml}$ blood was collected in plain bottle. Informed consent was taken from the individual subjects prior to blood collection. Blood was taken from antecubital vein of the subjects and $\alpha-1$ acid glycoprotein assay in serum was carried out by the method of Winzler RJ, et al. [14].

\section{Principle of the Test}

After removing heat coagulable proteins with perchloric acid, the orosomucoid which remains in the solution is precipitated by phosphotungstic acid and estimated by determining it carbohydrate content by reaction with an orcinol-sulphuric acid reagent, or its nitrogen by Kjeldahl nesslerization or its tyrosine content using Folin Ciocalteau reagent. The last of these is employed in the technique given below.

\section{Statistics}

The data was analyzed by the students' t test and the ANOVA test. Pearson's coefficient was applied for correlational analysis.

\section{Results}

The mean age (range), body mass index (BMI) and values of random blood sugar (RBS) are presented in Table 1. The control group participants were so chosen as to cover the age range of the test groups. Table 2 lists the values of orosomucoid in all three groups as mean \pm SD. Table 3 denoted the comparison between different groups and significance levels ( $\mathrm{p}$ values). In newly diagnosed type 2 diabetic patients (Group II) show higher level of orosomucoid in compare to control group(Group III) as depicts the significant $\mathrm{p}$ value $\left(<0.0001^{*}\right)$. It's also detected that the level of the orosomucoid is significantly higher in newly diagnosed type 2(Group II) in compare to newly diagnosed type 1(Group I) as denoted by significant $\mathrm{p}$ value $\left(<0.0001^{*}\right)$. Table 4 denoted correlation of RBS ( $r$ value) with orosomucoid level in different groups of patients. This $r$ value does not show any positive correlation with any types of patients.

\begin{tabular}{|c|c|c|c|}
\hline & $\begin{array}{c}\text { Type 1 Diabetes Mellitus(N=12) } \\
\text { (Mean } \pm \text { SD) }\end{array}$ & $\begin{array}{c}\text { Type 2 Diabetes Mellitus (N=25) } \\
\text { (Mean } \pm \text { SD) }\end{array}$ & $\begin{array}{c}\text { Control(n=30) } \\
\text { (Mean } \pm \text { SD) }\end{array}$ \\
\hline Age (years.) & $18.33 \pm 7.64$ & $48.22 \pm 7.11$ & $44.97 \pm 15.06$ \\
\hline BMI & $19.50 \pm 1.23$ & $24.03 \pm 1.46$ & $21.75 \pm 2.27$ \\
\hline RBS & $338.25 \pm 50.97$ & $193.26 \pm 35.30$ & $94.20 \pm 7.00$ \\
\hline
\end{tabular}

Table 1: The anthropometric data of the subjects participated in the study are presented in Table 1.

\begin{tabular}{|c|c|c|c|}
\hline Serum Level (Mg/D) & $\begin{array}{c}\text { Type 1 Diabetes } \\
\text { Mellitus(N=12) } \\
(\text { Mean } \pm \text { SD) }\end{array}$ & $\begin{array}{c}\text { Type 2 Diabetes Mellitus(N=25) } \\
\text { (Mean } \pm \text { SD) }\end{array}$ & $\begin{array}{c}\text { Control(N=30) } \\
\text { (Mean } \pm \text { SD) }\end{array}$ \\
\hline Orosomucoid(mg/dl) & $94.87 \pm 23.31$ & $181.93 \pm 31.94$ & $103.41 \pm 22.13$ \\
\hline
\end{tabular}

Table 2: The compare of mean value of orosomucoid in groups in Table 2.

\begin{tabular}{|c|c|c|c|}
\hline Comparison between groups & Level(mg/dl) & Level(mg/dl) & p value \\
\hline Comparison between Group I and Group III & $94.87 \pm 23.31(\mathrm{I})$ & $103.41 \pm 22.13(\mathrm{III})$ & 0.275 \\
\hline Comparison between Group II and Group III & $181.93 \pm 31.94(\mathrm{II})$ & $103.41 \pm 22.13(\mathrm{III})$ & $<0.0001^{*}$ \\
\hline Comparison between Group I and Group II & $94.87 \pm 23.31(\mathrm{I})$ & $181.93 \pm 31.94(\mathrm{II})$ & $<0.0001^{*}$ \\
\hline
\end{tabular}

Table 3: Comparison of level of orosomucoid (mg/dl) between different groups in Table-3 (p value $<0.05$ is considered significant). 


\section{Open Access Journal of Endocrinology}

\begin{tabular}{|c|c|c|c|}
\hline Parameter & Group I & Group II & Group III \\
\hline Orosomucoid & -0.15 & -0.03 & -0.05 \\
\hline
\end{tabular}

Table 4: Correlation of RBS with orosomucoid in all the groups ( $\mathrm{r}$ value).

Group I = Type 1 diabetes mellitus patient (newly diagnosed)

Group II = Type 2 diabetes mellitus patient (newly diagnosed)

Group III = Control

*denoted significant value

$\mathrm{n}=$ number of subjects

$\mathrm{SD}=$ Standard Deviation

BMI= Body Mass Index

RBS= Random Blood Sugar

\section{Discussion}

In this present project we were aimed to determine whether serum orosomucoid levels are altered in case of adult as well as adolescent diabetic patients. The level of serum orosomucoid were not elevated in twelve studied cases of adolescent diabetic patients, in fact there were significantly declined orosomucoid level $(94.87 \pm 23.31)$ in these cases in compare to control (103.41 \pm 22.13$)$. Even $\mathrm{p}$ value also shown statistically insignificant ( $\mathrm{p}$ 0.275). Some previous contradictory results were shown by some renounced scientific works done by renounced scientists like Crooke MA, et al. [15], who was shown that serum orosomucoid levels used to decline in case of adolescent diabetic patients which is supporting our findings. But contradictory result was shown by Gomes, et al. [16]. In their study there were significantly increase in serum value of orosomucoid in case of adolescent diabetic patients.

In case of twenty-five newly diagnosed adult diabetic patient there were significant elevation of serum orosomucoid level observed. Even $\mathrm{p}$ value was determined $<0.0001$ in compare with controls, which used to consider as statistically significant. This result had a co- agreement with most of the authors worked previously on orosomucoid level on adult diabetic patients and shown inflammatory markers tends to increase in adult diabetic patients. McMillan DE [17] shown that serum orosomucoid level used to increase in long termed adult diabetic patients as well as Festa A, et al. [18] shown that elevated levels of acute phase proteins and plasminogen activator inhibitor 1 predict the development of in case of insulin resistance type 2 diabetic patients. These all previous work supported our present findings.

In this present study if we analysis the value obtained of serum orosomucoid in case of adult as well as adolescent patients it will shown that in case of untreated adult diabetic patients the values are much higher than adolescent diabetics. But if we concentrated only on random blood sugar level in both type of patients, it was determined much more higher level in case of adolescent patients $(338.25 \pm 50.97 \mathrm{mg} / \mathrm{dl})$ than in adult diabetic patients(193.26 $\pm 35.30 \mathrm{mg} / \mathrm{dl})$. In spite of this huge difference of glycemic status, the level of inflammatory markers such as serum orosomucoid value is much higher in case of adult untreated diabetic patients. From this above finding we can predict that glycemic status of both untreated adolescent as well as adult diabetic used to not influenced by their current glycemic status. This finding is in accordance to early finding of Sriharan M, et al. [19]. Even it was also shown by Engstrom G, et al. [20], Schmidt MI, et al. [7], Duncan BB, et al. [21] and Pradhan AD, et al. [22] that inflammatory markes used to elevated well before the clinical manifestation of hyperglycemia developed. This also supported the thought that glycemic status may not related to activated innate immune system. But about decades before Allessandri G, et al. [23] shown that decrease plasma level of glucose decrease the level of acute phase reactants. Even study done by Sriharan, et al. [19] shown positive correlation between inflammatory markers and 2 hours post prandial blood glucose levels. The main basic mechanism for the augmented response needs to be well understand and stimulus of the response should be finding it out. Several numbers of hypothesis put forwards in support of this mechanism by Pickup JC, el at. [24] and Grimble RF, et al. [25], which included resistance to insulin, obesity, atherosclerosis, other complications of diabetes and maladaptation of normal innate immune mechanism due to environmental threats. It was also shown by Mohammad AV, et al. [26] that in post prandial state adipocytes secret number of proinflammatory cytokines. Later it was proposed by 'common soil theory' which used to evaluate the association of inflammatory markers with diabetes and development of atherosclerosis. Hyperglycemia and insulin resistance could promote inflammation and inflammation may be a factor linking diabetes mellitus to the development of atherosclerosis. Bayens JW and Thorpe SR [27] and even Brownlee M [28] shown that elevated level of serum glucose promotes inflammatory response by promoting oxidative stress by increasing the level of tumor necrosis factor kappa B. In this study present the mean BMI was found to be $19.5 \pm$ 


\section{Open Access Journal of Endocrinology}

1.23 in adolescent patient and $24.03 \pm 1.46$ in adult patients. No correlation was found between BMI and serum orosomucoid levels.

\section{Conclusion}

After analysis of whole study hence we can come to an initial conclusion that multiple factors are involved in development of innate immune response. From these above findings we can say in conviction that the role of low grade chronic inflammatory markers such as orosomucoid in case of adult diabetic patients are almost beyond doubt but its role in case of adolescent diabetic patients are still in contradictory phase, although the course of progression of disease and resulting complications in both type of diseases is almost same. Out of all one of a most fatal complication is developing of atherosclerosis resulting in cardiovascular disease. So we can come to a conclusion that although level of inflammatory markers such as orosomucoid is well associated and correlated with adult diabetes mellitus but much further work and follow up can be done to establish the definitive relation of level of inflammatory markers such as orosomucoid in pathogenesis of adolescent diabetic patients.

\section{References}

1. Craig ME, Hattersley A, Donaghue KC (2009) Definition, epidemiology and classification of diabetes in children and adolescents. Pediatr Diabetes 10(12): 3-12.

2. Patterson CC, Dahlquist GG, Gyurus E, Green A, Soltesz G, et al. (2009) Incidence trends for childhood type 1 diabetes in Europe during1989-2003 and predicted new cases 2005-20: a multicentre prospective registration study. Lancet 373(9680): 2027-2033.

3. Pugliese A (1995) Unraveling the genetics of insulin dependent type I diabetes: The search must go on. Diabetes Rev 7(1): 39-54.

4. Sartore S, Agostini C, Avogaro A (2007) Significance of endothelial progenitor cells in subjects with diabetes. Diabetes Care 30(5): 1305-1313.

5. Thorand B, Lowel H, Schneider A, Kolb H, Meisinger C, et al. (2003) C-reactive protein as a predictor for incident diabetes mellitus among middle-aged men: results from the MONICA Augsburg cohort study, 1984-1998. Arch Intern Med 163(1): 93-99.
6. Pradhan AD, Manson JE, Rifai N, Buring JE, Ridker PM (2001) Creactive protein, interleukin 6, and risk of developing type 2 diabetes mellitus. JAMA 286(3): 327-334.

7. Schmidt MI, Duncan BB, Sharrett AR, Lindberg G, Savage PJ, et al. (1999) Markers of inflammation and prediction of diabetes mellitus in adults (Atherosclerosis Risk in Communities study): a cohort study. Lancet 353(9165): 1649-1652.

8. Snijder MB (2001) C-reactive protein and diabetes type 2. Diabetologia 44(1): 115.

9. Spranger J, Kroke A, Mohlig M, Hoffmann K, Bergmann MM, et al. (2003) Inflammatory cytokines and the risk to develop type 2 diabetes: results of the prospective population based European Prospective Investigation Cancer and Nutrition (EPICN)- Potsdam study: Diabetes 52(3): 812-818.

10. Schmid K (1975) $\alpha-1$ acid glycoprotein. In: FW Putnam (Ed.), The plasma proteins. $2^{\text {nd }}(E d n)$, New York, Academic Press, pp: 184-228.

11. Tietz NW (1986) Amino acids and proteins. In: Textbook of clinical chemistry. WB Saunders Company, pp: 519-618.

12. Kushner I (1993) Regulation of the acute phase response by cytokines. Perspect Biol Med 36(4): 611622.

13. Taniuchi K, Chifu K, Hayashi N, Nakamachi $\mathrm{Y}$, Yamaguchi N, et al. (1981) A new enzymatic method for the determination of sialic acid and its application as a marker of acute phase reactants. Kobe J Med Sci 27(3): 91-102.

14. Winzler RJ (1995) Determination of serum $\alpha-1$ acid glycoprotein. In: Methods in Biochemical Analysis. Interscience Pub New York 2: 270.

15. Crook MA, Tutt P, Simpson H, Pickup JC (1993) Serum sialic acid and acute phase protein in type 1 and type 2 diabetes. Clin Chim Acta 219(1-2): 131-138.

16. Gomes MB, Piccirillo LJ, Nogueira VG, Matos HJ (2003) Acute phase proteins among patients with type1 diabetes. Diabetes Metab 29(4 pt 1): 405-411.

17. McMillan DE (1989) Increased levels of acute phase serum proteins in diabetes. Metabolism 38(11): 1042-1046. 


\section{Open Access Journal of Endocrinology}

18. Festa A, D Agostino R, Tracy RP, Haffner SM (2002) Elevated levels of acute phase proteins and plasminogen activator inhibitor 1 predict the development of type 2 diabetes: the insulin resistance atherosclerosis study. Diabetes 51(4): 1131-1137.

19. Sriharan M, Reichelt AJ, Opperman ML, Duncan BB, Mengue SS, et al. (2002) Total sialic acid and associated elements of the metabolic syndrome in women with and without previous gestational diabetes. Diabetes Care 25(8): 1331-1335.

20. Engstrom G, Stavenow L, Hedblad B, Lind P, Eriksson $\mathrm{KF}$, et al. (2003) Inflammation sensitive plasma protein, diabetes mortality and incidence of myocardial infarction and stroke: A population based study. Diabetes 52(2): 442-447.

21. Duncan BB, Schmidt MI, Offenbacher S, Wu KK, Savage PJ, et al. (1999) Factor VIII and other hemostasis variables are related to incident diabetes in adult: The Atherosclerosis Risk In Community (ARIC) study. Diabetes Care 22(5): 767-772.

22. Pradhan AD, Manson JE, Rifai N, Buring JE, Ridker PM, et al. (2001) C-reactive protein, interleukin-6 and risk of developing type2 diabetes mellitus. JAMA 286(3): 327-334.

23. Allessandri G, Raju K, Gullino PM (1983) Mobilization of capillary endothelium in vitro induced by effectors of angiogenesis in vivo. Cancer Res 43(4): 1790-1797.

24. Pickup JC, Crooke MA (1998) Is type 2 diabetes mellitus a disease of the innate immune system? Diabetologia 41(10): 1241-1248.

25. Grimble RF (2002) Inflammatory status and insulin resistance. Curr Opin Cli Nutr Metab 5(5): 551-559.

26. Mohammed AV, Goodrick S, Rawesh A, Katz DR, Miles JM, et al. (1997) Subcutaneous adipose tissue releases interleukin-6, but not tumor necrosis factor $\alpha$, in vivo. J Clin Endocrinol Metab 82(12): 4196-4200.

27. Bayens JW, Thorpe SR (1999) Role of oxidative stress in diabetic complications: a new perspective on an old paradigm. Diabetes 48(1): 1-9.

28. Brownlee M (2001) Biochemistry and molecular cell biology of diabetic complication. Nature 414 (6865): 813-820.

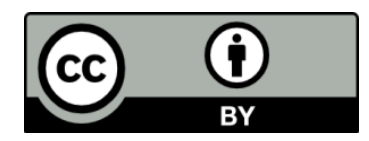

